\title{
Double Guidewire Technique versus Transpancreatic Sphincterotomy for Difficult Biliary Cannulation
}

\author{
Mohie Eldin Mohamed Amer, Mohamed Abdel Rasheed Abdel Khalik Allam and Mohamed \\ Hamza Al-Sisi* \\ Department of Tropical Medicine, Faculty of Medicine, Al-Azhar University \\ *Corresponding author: Mohamed Hamza Al-Sisi, Mobile: (020)1095667072, E-Mail: abo_hamaza2751@yahoo.com
}

\begin{abstract}
Background: The standard biliary cannulation technique has been reported to fail in approximately 5$20 \%$ of cases so, several supplementary techniques have been recommended to facilitate access to the common bile duct (CBD); Double-guidewire technique (DGT) and transpancreaticsphincterotomy (TPS) are effective method in cases of standard biliary cannulation failure.

Objective: To compare the outcomes between DGT and TPS in patients with difficult biliary cannulation regarding the procedure duration, success rate and complications.

Patients and Methods: This was a randomized study conducted in Al-Hussein University Hospital, Endoscopy Unit in the period between May, 2016 to October, 2017. A total of 40 patients, who bile duct cannulation was not possible and selective pancreatic duct cannulation was achieved were randomized into DGT $(n=19)$ and TPS $(n=21)$ groups. DGT or TPS was done for selective biliary cannulation. We measured the technical success rates of biliary cannulation, median cannulation time, and procedure related complications.
\end{abstract}

Results: The distribution of patients after randomization was balanced, and both groups were comparable in baseline characteristics. There was no significant difference between both groups regarding age and sex distribution, clinical presentation, laboratory findings and sonographic findings. Successful cannulation rate and mean cannulation times in DGT and TPS groups were $94.7 \%$ vs $95.2 \%$ and $20.1 \pm 8.7 \mathrm{~min}$ vs $21.5 \pm 7.8 \mathrm{~min}, \mathrm{P}=0.602$, respectively. There was no significant difference between the two groups.

Conclusion: When free bile duct cannulation was difficult and selective pancreatic duct cannulation was achieved, DGT and TPS facilitated biliary cannulation and showed similar success rates. However, post-procedure pancreatitis and Cholangitis were significantly higher in the DGT group.

Keyword: ERCP, Endoscopic Retrograde Cholangiopancreatography, DGT, TPS; Transpancreaticsphincterotomy.

\section{Introduction}

Selective biliary cannulation is a crucial step for therapeutic endoscopic retrograde cholangiopancreatography (ERCP) ${ }^{(1)}$. In the hands of experienced endoscopists, successful biliary cannulation rates are higher than $90 \%{ }^{(2)}$.

However, in some cases, bile duct (BD) cannulation can be difficult because of special anatomical features, inflammatory processes, and adenomas of the papilla or periampullary diverticulum ${ }^{(3)}$.

In the past few years, various efforts have been made to develop alternative endoscopic techniques, with the goal of increasing the rate of successful biliary cannulation $^{(4)}$.

The use of a guidewire to physically occupy the pancreatic duct (PD), also known as the double-guidewire technique (DGT). Sinceits first description, this method has been used with promising results in cases of complex biliary cannulation, especially in patients with a distorted BD anatomy caused by neoplasia or atypical morphology of the 
$\operatorname{ampulla}^{(5)}$.

Transpancreaticsphincterotomy

(TPS) using a guidewire, another technique for difficult biliary cannulation. A sphincterotomy over the guidewire in the PD helps to cannulate the biliary orifice because the cut either opensthe BD orrunsalongthe side of the duct, thus exposing the duct'sanatomy ${ }^{(6)}$.

Double-guidewire technique and TPS might facilitate biliary cannulation and achieving a success rate of $47-93 \%$ in patients who fail standard $\mathrm{BCH}$ owever, postERCP pancreatitis has been reported to occur with DGT and TPS in $0 \%$ to $25 \%$ of patients $^{(\mathbf{3})}$.

\section{Aim of the work:}

It is to compare the outcomes of DGT and TPS in patients with difficult biliary cannulation.

\section{Patients and Methods}

This randomized study was carried out at Al-Hussein University Hospital, ERCP endoscopy unit, during the period between May 2016 to October 2017, when 504 cases of ERCPs were performed and 40 patients were enrolled in this study. Consecutive patients were considered for inclusion if they underwent ERCP with clear indication of biliary access.

Among these patients, those in whom free cannulation of the BD was not possible and selective PD cannulation was achieved without difficulty were enrolled in this study.

Enrolled patients were randomly assigned to either the DGT group or the TPS group. Patients were excluded for any of the following reasons: (1) Age of less than 18 years; (2) Subjects who underwent priorbiliary or pancreatic sphincterotomy or dilatation or stenting of either duct; (3) Acute pancreatitis at the time of the procedure; (4) History of pancreatico-biliary surgery except cholecystectomy; and (4) Intrauterine pregnancy.

We compared both techniques for a maximum of 10 extra attempts after randomization which is common $\mathrm{BD}$ (CBD) cannulation by each method. Thus, we did not impose a time limit for CBD cannulation.

For all patient clear written consent, full clinical and routine laboratory assessment and abdominal sonography were done.

ERCP was performed in the standard manner using a side-view endoscope (Fujinon ED-250XTDuodenoscope). After selective cannulation of the common bile duct by the catheter, cholangiography was performed to confirm the diagnosis. A0.035inch guidewire (Boston Scientific, Corp, MA, $U S A$ ) was inserted into the bile duct through the catheter.

ERCP standard maneuver: After cannulation of the CBD, an initial cholangiogram was taken and the diameter of the CBD at its most dilated part was assessed, in comparison with the diameter of the shaft of the endoscope.

Double-guidewire technique (DGT): in cases of failed CBD cannulation and the guidewire selectively entered the pancreatic duct on each attempt, guidewire was placed into the pancreatic duct to facilitate wire guided cannulation of the common bile. The technique basically consisted of leaving the initial guidewire placed in the main pancreatic duct then sphincterotome was reloaded with another guide wire and advanced through the operating channel of the duodenoscope beside the original guidewire and the second guidewire.

Transpancreaticsphincterotomy (TPS): After inserting the guidewire deeply into the PD without difficulty, the tip of a standard traction sphincterotome was wedged into the pancreatic orifice, and a sphincterotomy was performed with a cutting wire along the biliary direction at 11 o'clock, aiming to expose the BD orifice. The BD orifice was exposed to the left and either below or above the pancreatic orifice. Then biliary cannulation was attempted. 
All patients were monitored at least for 24 hours after the procedure to detect symptoms and signs of complications (e.g. tachycardia, hypotension, fever, vomiting andlor abdominal pain). Serum amylase was done four hours postERCP. Patients were then either hospitalized or followed up by phone contact.

Calculations of the mean (M), standard deviation (SD) were used for statistical evaluation. The categorical outcomes were compared using $\chi 2$ test or Fisher's exact test, where appropriate. The mean ages were compared by using Student's $t$ test. All $P$-values reported were two-sided, with the significant value of $<0.05$. SPSS software (version 16.0; SPSS, Chicago, IL, USA) was used to analyze the outcome. In that regard, there was no correction made to the $\mathrm{P}$ value for the comparison of post- ERCP pancreatitis rates because that comparison was considered to be the focal point when making sample size calculations. All other statistical tests of outcome results should be considered to be secondary, and their results should be taken as descriptive only.

\section{Results Characteristics of patients}

During the study period, 504 ERCPs were performed at Al-Hussin University Hospital, Endoscopy Unit. We excluded 32 patients for the following reasons: age of $<18$ years (Two patients); previous endoscopic sphincterotomy or endoscopic papillary balloon dilation (19 patients); acute pancreatitis before ERCP (10 patients); and pregnancy (One patient).

After this exclusion, ERCP was attempted in the remaining 472 patients with the native papilla of Vater with standard cannulation technique. In 425 patients (90.04\%), selective BD cannulation was achieved within 10 attempts and $10 \mathrm{~min}$; difficult biliary cannulation occurred in $47(9.95 \%)$ patients. Of these, PD cannulation was also not achieved in 7 patients and needleknife precut was done.

Finally, 40 patients in whom deep PD guidewire cannulation was achieved were enrolled in this study and randomly assigned to the DGT group (19 patients) or the TPS group (21 patients) (Figure 1).

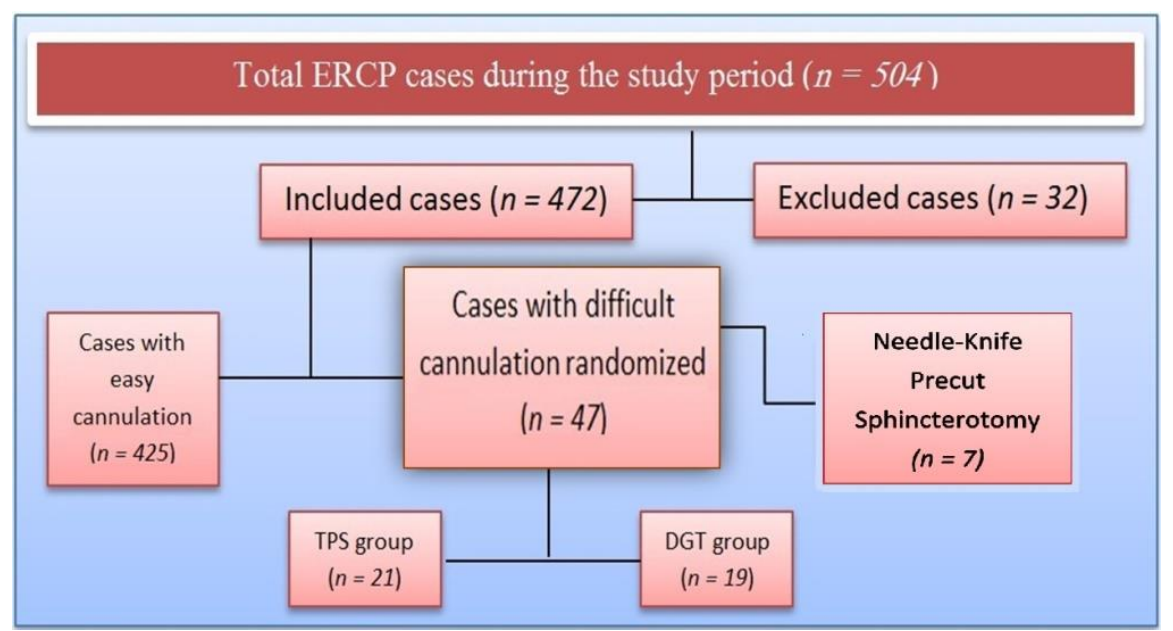

Figure (1): Flow diagram of endoscopic retrograde cholangiopancreatography (ERCP) procedures. DWT, double-guidewire technique; TPS, transpancreaticsphincterotomy.

The distribution of patients after randomization was balanced, and both groups were comparable in baseline characteristicssuch as ERCP indication, devices used, ERCP findings, and maneuvers. There was no significant difference between both groups regarding age and sex distribution, clinical presentation, laboratory findings and sonographic findings (Table 1). 
Table 1/ Baseline characteristics, procedures, successful cannulation rate, median cannulation time, and procedure-related complications of the double-guidewire technique and transpancreaticsphincterotomy groups:

\begin{tabular}{|c|c|c|c|c|}
\hline \multirow{2}{*}{\multicolumn{2}{|c|}{$\begin{array}{l}\text { Table 1/ Baseline characteristics, procedures, } \\
\text { successful cannulation rate, median cannulation } \\
\text { time, and procedure-related complications of the } \\
\text { double-guidewire technique and } \\
\text { transpancreaticsphincterotomy groups }\end{array}$}} & DGT group & TPS group & \multirow{2}{*}{$\begin{array}{c}P \\
\text { value }\end{array}$} \\
\hline & & $\mathbf{n}=\mathbf{1 9}$ & $\mathbf{n}=\mathbf{2 1}$ & \\
\hline \multicolumn{2}{|c|}{ Age (year) } & $56.16 \pm 13.171$ & $58.48 \pm 17.792$ & 0.645 \\
\hline \multirow[t]{2}{*}{ Sex } & Male & $9(47.40)$ & $9(42.90)$ & \multirow[t]{2}{*}{0.775} \\
\hline & Female & $10(52.60)$ & 12(57.10) & \\
\hline \multirow{5}{*}{$\begin{array}{l}\text { Indication of } \\
\text { ERCP }\end{array}$} & CBD stone & $9(47.40)$ & $10(47.60)$ & \multirow[t]{5}{*}{0.882} \\
\hline & Pancreatic cancer & $5(26.30)$ & $4(19.00)$ & \\
\hline & Cholangiocarcinoma & 3(15.80) & $5(23.80)$ & \\
\hline & Other bile duct disease & $2(10.50)$ & $1(4.80)$ & \\
\hline & Other pancreatic disease & $\mathbf{0}(\mathbf{0 . 0 0})$ & $1(4.80)$ & \\
\hline \multicolumn{2}{|l|}{ PADD } & $4(21.05)$ & $3(14.28)$ & \multirow[t]{4}{*}{0.646} \\
\hline Type I & & $1(5.30)$ & $0(0.00)$ & \\
\hline Type II & & $3(15.80)$ & $2(9.50)$ & \\
\hline Type III & & $0(0.00)$ & $1(4.80)$ & \\
\hline \multirow{4}{*}{ ERCP maneuver } & Contrast injection in PD & 19(100) & $20(95.24)$ & 0.335 \\
\hline & EST & $14(37.0)$ & $18(76.20)$ & 0.855 \\
\hline & CBD stone extraction & $7(36.80)$ & $6(28.60)$ & 0.577 \\
\hline & EPBD & $4(21.10)$ & $1(4.80)$ & 0.120 \\
\hline \multirow{3}{*}{$\begin{array}{l}\text { Successful } \\
\text { cannulation }\end{array}$} & First trial & $15(78.90)$ & $18(85.70)$ & 0.821 \\
\hline & Including second trial & 18(94.73) & $20(95.23)$ & 0.821 \\
\hline & Failure of cannulation & $1(5.30)$ & $1(4.80)$ & 0.821 \\
\hline \multicolumn{2}{|c|}{$\begin{array}{l}\text { Median cannulation } \\
\text { Time min (IQR) }\end{array}$} & $20.16 \pm 8.751$ & $21.52 \pm 7.679$ & 0.602 \\
\hline \multicolumn{2}{|c|}{ Post-ERCP hyperamylasemia } & $6(31.60)$ & $5(23.80)$ & 0.583 \\
\hline \multicolumn{2}{|c|}{ Post-ERCP pancreatitis (PEP) } & $9(47.36)$ & $2(9.52)$ & $0.013 *$ \\
\hline \multicolumn{2}{|c|}{ Mild PEP } & $7(36.80)$ & $1(4.80)$ & $\mathbf{0 . 0 1 7}$ \\
\hline \multicolumn{2}{|c|}{ Moderate to severe PEP } & $2(10.50)$ & $1(4.80)$ & 0.596 \\
\hline \multicolumn{2}{|c|}{ Bleeding } & $\mathbf{0}(\mathbf{0 . 0 0})$ & $1(4.80)$ & 1.000 \\
\hline \multicolumn{2}{|l|}{ Cholangitis } & $8(42.10)$ & $1(4.80)$ & $0.007 *$ \\
\hline \multicolumn{2}{|l|}{ Cholecystitis } & 0 & 0 & \\
\hline \multicolumn{2}{|l|}{ Perforation } & 0 & 0 & \\
\hline
\end{tabular}

*significant; ERCP: Endoscopic retrograde cholangiopancreatography; DGT: Double guidewire technique; PD: Pancreatic duct; EST: Endoscopic sphincterotomy; CBD: Common bile duct; GB: Gallbladder; PADD: Periampullary duodenal diverticulum; EPBD: Endoscopic papillary balloon dilatation; IQR: Inter-quartile range; PEP: Post endoscopic retrograde cholangiopancreatography pancreatitis; TPS: Transpancreaticsphincterotomy. 


\section{Successful BD cannulation rates and median cannulation time}

Within the limit of 10 extra attempts, initial successful biliary cannulation was achieved in 15 of the $19(78.9 \% \%)$ patients in the DGT group and 18 of the $21(85.7 \%)$ patients in the TPS group. Additional successful biliary cannulation was achieved in three and two patients using the initial technique in the second ERCP trial. Thus, the overall successful biliary cannulation rates, including the repeat ERCPs, were $94.7 \%(18 / 19)$ in the DGT group and $95.2 \%$ $(20 / 21)$ in the TPS group. There was no significant difference in the initial and final cannulation rates of BD between the two groups (Table 1). In patients who underwent successful biliary cannulation, the mean time of cannulation was $14.4 \mathrm{~min}$ in the DGT group and $14.6 \mathrm{~min}$ in the TPS group; the difference between the two groups was not statistically significant (Table 1).

\section{Post-ERCP hyperamylasemia and pancreatitis}

The overall incidence of post-ERCP hyperamylasemia was $31.6 \%(6 / 19)$ in the DGT group and $23.8 \%(5 / 21)$ in the TPS group. There was no significant difference between the two groups. Post-ERCP pancreatitis developed in $38.2 \%(13 / 34)$ of the DGT group and $10.8 \%$ (4/37) of the TPS group. Post-ERCP pancreatitis was significantly higher in the DGT group than in the TPS group $(P=0.013)$. However, most cases of pancreatitis were mild. Moderate or severe pancreatitis developed rarely in both groups (Table 1).

\section{Other complications}

One episode of bleeding occurred in the TPS group (4.8\%), and nobleeding was detected in the DGT group. Acute cholangitis developed in $42.1 \%(8 / 19)$ of the DGT group and $4.8 \%$ $(1 / 21)$ of the TPS group. There was no statistically significant difference between the groups in the rates of procedure-related bleeding. However, the incidence of cholangitis was significantly higher in the DGT group than in the TPS group $\left(\mathrm{P}=0.007^{*}\right)$. Acute cholecystitis and perforation were not detected in any group (Table $1)$.

\section{Discussion}

In the 1990s, new techniques for overcoming difficult biliary cannulation, such as DGT, TPS, and wire-guided biliary cannulation over the PD stent were introduced $^{(7)}$. The superior rate of biliary cannulation when using DGT has been attributed to the capability of the pancreatic guidewire to straighten both the PD and $\mathrm{BD}$ while at the same time occupying the PD, thus facilitating biliary cannulation and preventing repeated pancreatic cannulation ${ }^{(8)}$.

One prospective randomized study reported by Maeda $\boldsymbol{e t} \boldsymbol{a l} .{ }^{(9)}$, compared DGT with standard methods, and indicated a higher cannulation success rate (93\%) with DGT with no apparent added risk of post-ERCP pancreatitis. However, in the most recent prospective randomized multicenter study by Herreros de Tejada et al. ${ }^{(10)}$, DGT was not superior to standard cannulation techniques (success rates of $47 \%$ and $56 \%$, respectively)and may have been associated with a higher risk of post- ERCP pancreatitis (17\% and $8 \%$, respectively).

TPS technique is a relatively new precut technique among the various precut techniques, which was first described in 1995. Previous studies have found that TPS is a safe and effective procedure in patients with difficult bile duct access ${ }^{(\mathbf{1 1})}$. However, the use of the precut technique for achieving deep cannulation of the bile duct is not recommended for inexperienced endoscopists as it is claimed to increase postERCP complications ${ }^{(\mathbf{1 2})}$.

TPS can facilitate cannulation of the biliary orifice because the cut either opens the $\mathrm{BD}$ or runs along the side of the duct, thus exposing the orifice Akashi et al. (13), published a prospective series in which TPS was successful in approximately $60 \%$ of the patients immediatelyand in $95 \%$ with repeated ERCP. However, the complication rates of TPS were significantly higher than those of standard biliary sphincterotomy (9.9\% vs $0.8 \%, \mathrm{P}<0.001)$.

In another prospective study by Kahaleh et al. ${ }^{(14)}$, the primary success rate of pancreatic sphincterotomy was $85 \%$, which, when combined with the needle-knife 
technique, rose to $95 \%$. The rate of postERCP pancreatitis was $8 \%$, which was not different from that of conventional biliary sphincterotomy.

Our results show that the two techniques facilitate selective biliary cannulation with a similar success rate. The initial success rate of DGT in our study was $78.9 \%$, and the final success rate, including the repeat ERCP, was $94.7 \%$. This result is similar to that reported by Maeda ${ }^{(9)} 92.6 \%$, but higher than that reported by Herreros de Tejada $^{(10)} 47 \%$.

In the latter study, the difficult cannulation rates were as high as $49.5 \%$ and $22 \%$. In comparison, the difficult biliary cannulation rate in our study was lower and more comparable with the experience in highvolume centers. Our difficult biliary cannulation rate was only $9.95 \%$, which represented a truly difficult biliary cannulation group ${ }^{(\mathbf{1 3})}$.

In our study, the initial success rate of TPS was $85.7 \%$, and the final success rate was $95.2 \%$. These results are similar to those reported elsewhere ${ }^{(\mathbf{1 4})}$.

The incidence of post-ERCP pancreatitis after DGT was significantly higher than that after TPS (47.3\% vs $9.6 \%, \mathrm{P}$ $=0.013$ ).

The overall post-ERCP pancreatitis rate in this study was $27.5 \%$ (11/40). This is similar to those of previous studies, and most cases of pancreatitis were mild. However, in contrast to the other studies, we did not perform prophylactic PD stenting in any of the cases. The PD stent facilitates biliary cannulation and prevents post-ERCP pancreatitis, but is not usually used in Egypt because the costs of PD stents for prevention of post-ERCP pancreatitis and the financial burden of patients are substantially increased by their use.

Another difference is that we did not use any pharmacologic agents for post-ERCP pancreatitis, such as protease inhibitors, which are widely used by Japanese endoscopists. This might have lowered the frequencyof post-ERCP pancreatitis in previous studies. Problems with using a pancreatic guide wire include the potential for injuring branch ducts and the failure to place the guide wire deeply enough into a tortuous mainduct. In our study, guide wire insertion into the PD was performed under the guidance of contrast and fluoroscopy to minimize branch duct injury. However, repeated PD injection of contrast is one of the risk factors of Post-ERCP pancreatitis.

The incidence of cholangitis after DGT was almost eight times higher than that after TPS (42.1\% vs $4.8 \%, \mathrm{P}=0.007)$; and this difference was statistically significant. Patients with cholangitis had CBD stonesor CBD stricture. Therefore, we believe that the difference in cholangitis incidence was due to a difference not in methods, but in patients' characteristics.

One patient from TPS group developed post-sphincterotomy bleeding, and was controlled by diluted epinephrine injection. No blood transfusion was needed. According to the standard definition, this patient was classified as mild bleeding.

Our study has some limitations. First, the number of enrolled patients was relatively small, and the study was conducted in a single endoscopy unite. We enrolled only 40 patients with difficult cannulation from among a total of 504 patients $(7.9 \%)$ who presented for ERCP during the study period. This may have influenced the interpretation of the difference in success and post-ERCP pancreatitis rates. Therefore, a larger study is necessary to overcome this limitation. However, this also demonstrates that our study included truly difficult cases of BC. Second, information regarding the number of PD injections and patients with sphincter of Oddi dysfunction were not collected. This is one of the main limiting factors in drawing a firm conclusion regarding the role of guide wire insertion in the PD in post-ERCP pancreatitis.

We could conclude that the DGT and TPS facilitated biliary cannulation and showed similar success rates. However, the incidence of post procedure pancreatitis and cholangitis was significantly higher in the DGT group. Therefore, we suggest that the use of TPS when the standard biliary cannulation technique fails and PD 
cannulation is achieved is effective and has an acceptable complication profile. Further large-scale multicenter studies are needed.

\section{References}

1- Kawai K, Akasaka Y, Murakami K et al. (1974): Endoscopic sphincterotomy of the ampulla of Vater. Gastrointestinal Endoscopy, 20 (4) 148-151.

2- Ramirez F, Dennert $B$ and Sanowski $R$ (1999): Success of repeat ERCP by the same endoscopist. Gastrointest Endosc., 49:58-61.

3- Masci E, Mariani A, Curioni Set al. (2003): Risk factors for pancreatitis following endoscopic retrograde cholangiopancreatography: a metaanalysis. Endoscopy, 35:830-834.

4- Yasuda I and Itoi T (2013): Recent advances in endoscopic management of difficult bile duct stones. Digestive Endoscopy, 25 (4) 376-385.

5- Herreros A, Calleja J, Díaz G et al. (2009): Double-guidewire technique for difficult bile duct cannulation: a multicenter randomized, controlled trial. Gastrointest Endosc., 70:700-709.

6- Min J, Jae C, Byung M et al. (2015): Wire-guided cannulation over a pancreatic stent versus double guidewire technique in patients with difficult biliary cannulation. BMC Gastroenterology, 15:150-161.

7- Gyökeres T, Duhl J, Varsányi $\mathrm{M}$ et al. (2003): Double guide wire placement for endoscopic pancreaticobiliary procedures. Endoscopy, 35: 95-96.
8- Gotoh Y, Tamada K, Tomiyama T et al. (2001): A new method for deep cannulation of the bile duct by straightening the pancreatic duct. Gastrointest Endosc., 53: 820-822.

9- Maeda S, Hayashi H, Hosokawa O et al. (2003): Prospective randomized pilot trial of selective biliary cannulation using pancreatic guide-wire placement. Endoscopy, 35: 721724.

10-Herreros de Tejada A, Calleja JL, Díaz G et al. (2009): Doubleguidewire technique for difficult bile duct cannulation: a multicenter randomized, controlled trial. Gastrointest Endosc., 70: 700-709.

11-Choudhary A,Winn J, Siddique $S$ et al. (2014): Effect of precut sphincterotomy on post-endoscopic retrograde cholangiopancreatography pancreatitis: A systematic review and meta-analysis. World J. Gastroenterol., 20: 4093-101.

12-Webb $K$ and Saunders $M$ (2013): Endoscopic management of malignant bile duct strictures. Gastrointest. Endosc. Clin. N. Am., 23: 313-31.

13- Akashi R, Kiyozumi T, Jinnouchi $\mathrm{K}$ et al. (2004): Pancreatic sphincter precutting to gain selective access to the common bile duct: a series of 172 patients. Endoscopy, 36: 405410.

14-Kahaleh M, Tokar J, Mullick $T$ et al. (2004): Prospective evaluation of pancreatic sphincterotomy as a precut technique for biliary cannulation. Clin. Gastroenterol. Hepatol., 2: 971-977. 